\title{
Meiotic studies in Largus rufipennis (Castelnau) (Largidae, Heteroptera). II. Reciprocal translocation heterozygosity
}

\author{
M.J. BRESSA ${ }^{1,2}$, A.G. PAPESCHI ${ }^{2}$, L.M. MOLA ${ }^{2}$ and M.L. LARRAMENDY ${ }^{1}$ \\ ${ }^{1}$ Laboratorio de Citogenética, FNC, Universidad Nacional de La Plata, La Plata, Argentina. ${ }^{2}$ Ge- \\ nética, Departamento de Ciencias Biológicas, Universidad de Buenos Aires, Argentina.
}

\begin{abstract}
SUMMARY - Specimens of Largus rufipennis (Castelnau) (Largidae, Heteroptera) from three different populations from Argentina (Itaembé, Misiones Province; Tornquist and Ciudad Universitaria, Buenos Aires Province) were cytogenetically studied. Meiotic characteristics of these populations are compared with previous reports on the species. In the population from Itaembe, heterozygosity for a reciprocal translocation was encountered; this finding is the first report for this type of chromosome rearrangement in the order Heteroptera. The role of reciprocal translocations in karyotype evolution in organisms with holokinetic chromosomes is analyzed and discussed.
\end{abstract}

Key words: reciprocal translocation heterozygosity; holokinetic chromosomes; Heteroptera; karyotype evolution.

\section{INTRODUCTION}

Among the principal mechanisms of karyotype evolution in the holokinetic chromosomes of Heteroptera, autosomal fusions and both autosomal and sex chromosome fragmentations (which originate multiple sex chromosome determining systems) can be included (Ueshima 1979; Manna 1984; Thomas 1987; PAPESCHI 1994, 1996). Other chromosome rearrangements such as inversions have been rarely reported (PAPESCHI and Mola 1990) and the occurrence of reciprocal translocations have never been described within the order. So far, the latter kind of rearrangement has seldom been reported in other groups with holokinetic chromosomes; it has only been described in Luzula purpurea (Juncaceae) (CASTRo et al. 1954; NoRDENSKiöld 1963), in Myzus persicae (Homoptera) (BLACKMAn and TAKAdA 1975, 1977; Blackman et al. 1995) and in a few species of Buthidae (Scorpionida) (Piza 1948, 1951, 1957; Takahashi 1976; Shanahan 1989a).

Largus rufipennis (Largidae, Heteroptera) has two major chromosome characteristics that make it suitable for cytogenetic analysis: a low diploid number $(2 n=13)$ and chromosomes of large size. Up to date, two populations of this species have been analyzed, one from Brazil (PIzA 1946) and the other 
from Argentina (Mola and PAPESCH 1993). The Argentinian population was very heterogeneous with respect to chiasma frequency and distribution; desynaptic univalents as well as ring bivalents were observed in a variable frequency among individuals; a supernumerary chromosome (B chromosome) was detected in some individuals and was associated with an increase in chiasma frequency. In the Brazilian population neither univalents nor B chromosomes were reported, and although ring bivalents were present, the meiotic configurations were misinterpreted.

In the present report, Argentinian specimens from Itaembé (Misiones Province), Tornquist and Costanera Norte (Buenos Aires Province) were cytogenetically analyzed. The meiotic characteristics in the three different populations is compared; heterozygosity for a reciprocal translocation was observed in the population from Itaembé, this being the first report of this kind of chromosome rearrangement in the order Heteroptera (UESHIMA 1979; ManNA 1984). The origin and meiotic behaviour of the translocation quadrivalent is described and interpreted. The meiotic and genetic consequences of reciprocal translocations in holokinetic chromosomes are analyzed, and the potential role of this kind of rearrangement in the karyotype evolution of holokinetic chromosomes is discussed.

\section{MATERIALS AND METHODS}

Six adult males of Largus rufipennis (Castelnau) from Itaembé (Misiones Province), eleven from Tornquist (Buenos Aires Province) and nine from Costanera Norte (Buenos Aires Province) (Argentina) were fixed in the field in 3:1 methanol: glacial acetic acid, and kept at $4^{\circ} \mathrm{C}$ until analysis. Afterwards, gonads were dissected free and kept in $70 \%$ ethanol at $4^{\circ} \mathrm{C}$. Slides were prepared by the squash technique in 2 percent iron propionic haematoxylin following standard procedures. Mean chiasma frequency within and among the three populations was compared by means of a two level nested ANOVA, and GT2 non-planned comparisons (SoKAL and RoHLF 1981).

\section{RESULTS}

Largus rufipennis possess $2 n=12+\mathrm{XO}$ (male) (Fig. 1a). In five of the six individuals from Itaembe (specimens 2-6) and in all the individuals from Buenos Aires Province (Tornquist and Costanera Norte) six homomorphic bivalents plus the $\mathrm{X}$ chromosome univalent were observed at meiosis; one chromosome pair is remarkably larger than the others (Fig. 1a-c). Bivalents present one or two chiasmata (Fig. 1c) and a few cells with up to four ring bivalents were observed. At both metaphase plates the $\mathrm{X}$ chromosome lies outside the ring of autosomes (Fig. 1d, e). At anaphase I autosomal bivalents 


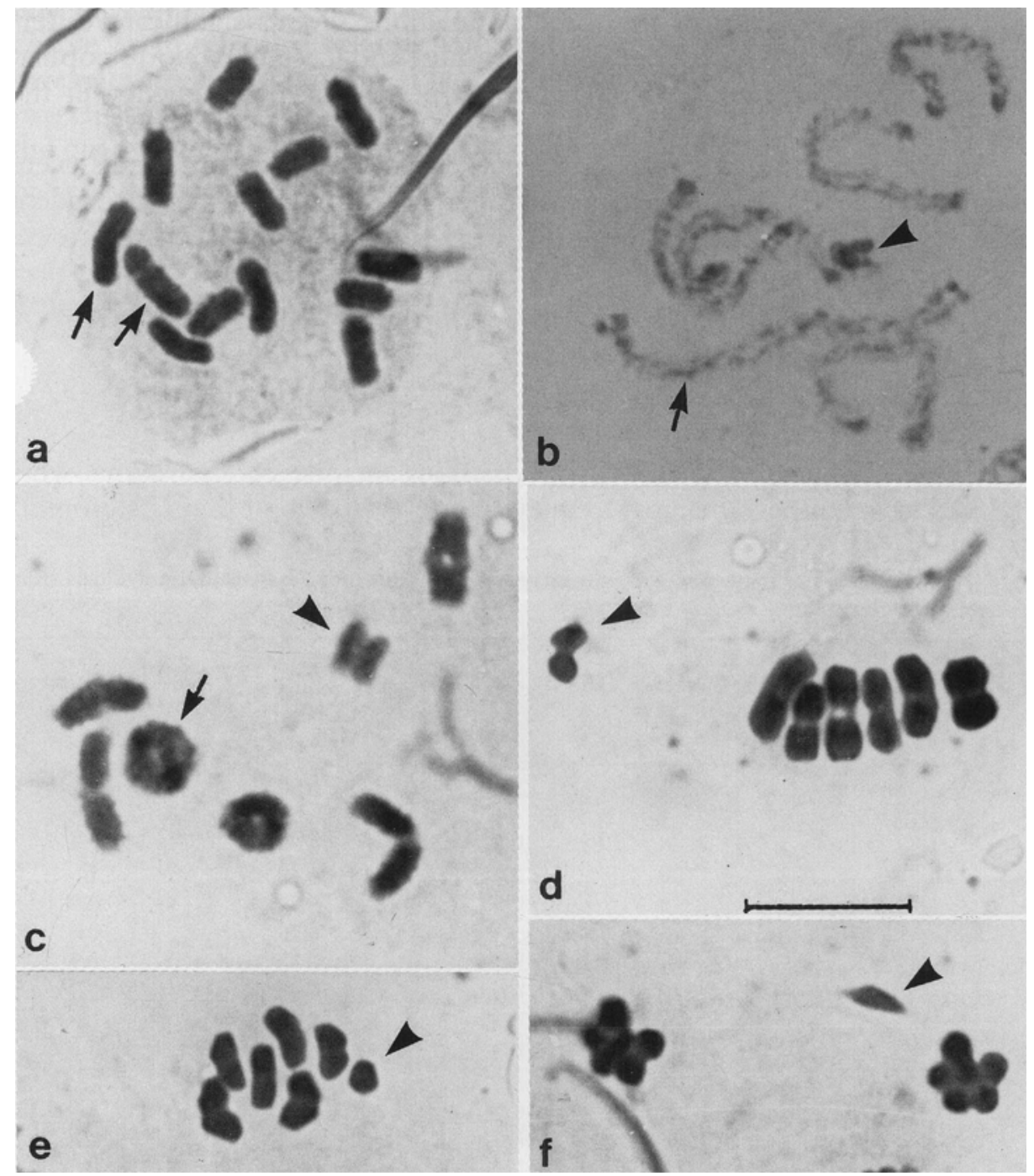

Fig. 1. - Meiosis in Largus rufipennis (standard karyotype). a) Mitotic prometaphase; b) pachytene; c) diakinesis; d) metaphase I; e) metaphase II; f) telophase II. Arrows point the largest bivalent; arrowheads point the $\mathrm{X}$ chromosome. $\mathrm{Bar}=10 \mu \mathrm{m}$.

divide reductionally, and the $\mathrm{X}$ separates its chromatids; at anaphase II the $\mathrm{X}$ segregates to one pole, lagging behind the autosomes (Fig. 1f).

Mean chiasma frequency varies among the three populations (Table 1). In the Itaembé population the mean number of chiasmata per cell is 6,62 (range 6,78-6,25), while in the Tornquist population is 6,28 (range 6,58-6,05) and in the Costanera Norte population is 6,18 (range 6,31-6,05). The comparison of 
mean chiasma frequency of the three populations reveals significant differences $(\mathrm{P}<<0,01)$; differences between Tornquist and Costanera Norte populations are not significant $(\mathrm{P}>0,05)$ whereas mean chiasma frequency in the Itaembé population is significantly higher $(\mathrm{P}<0,05)$.

In the three populations individuals with cells with univalents were detected (Table 1). All the specimens from Itaembé present a low univalent frequency $(0-2,4 \%)$ while in the individuals from Tornquist and Costanera Norte univalent frequency was more variable $(0-11,11 \%$ and $0-6,48 \%$, respectively). In none of the three populations B chromosomes were observed.

\section{Meiotic behaviour of the reciprocal translocation beterozygote}

In the specimen 1 from Itaembé, various meiotic configurations were observed at diakinesis, the most frequent being: 6 II (two of them heteromor-

TABLE 1 - Mean chiasma frequency and percentage of cells with univalents in the individuals from Misiones and Buenos Aires (Bs. As.) Provinces.

\begin{tabular}{|c|c|c|c|c|}
\hline Procedence & Individual & $\begin{array}{l}\text { Number } \\
\text { of cells }\end{array}$ & $\begin{array}{l}\text { Mean chiasma } \\
\text { frequency } \\
\text { at Diakinesis- } \\
\text { Metaphase I }\end{array}$ & $\begin{array}{l}\% \text { of cells with } \\
\text { univalents }\end{array}$ \\
\hline \multirow[t]{6}{*}{ Itaembé (Misiones) } & 1 & 236 & 6,86 & see Table 2 \\
\hline & 2 & 233 & 6,78 & 1,3 \\
\hline & 3 & 124 & 6,74 & 2,4 \\
\hline & 4 & 101 & 6,59 & 1 \\
\hline & 5 & 117 & 6,51 & 0,9 \\
\hline & 6 & 89 & 6,25 & 0 \\
\hline \multirow[t]{11}{*}{ Tornquist (Bs. As.) } & 1 & 142 & 6,58 & 0,7 \\
\hline & 2 & 103 & 6,46 & 2,91 \\
\hline & 3 & 76 & 6,42 & 0 \\
\hline & 4 & 183 & 6,39 & 8,74 \\
\hline & 5 & 95 & 6,35 & 1 \\
\hline & 6 & 95 & 6,32 & 1,05 \\
\hline & 7 & 199 & 6,26 & 0,5 \\
\hline & 8 & 51 & 6,12 & 0 \\
\hline & 9 & 190 & 6,12 & 0 \\
\hline & 10 & 278 & 6,09 & 2,52 \\
\hline & 11 & 54 & 6,05 & 11,11 \\
\hline \multirow[t]{9}{*}{ Costanera Norte (Bs. As.) } & 1 & 117 & 6,31 & 0 \\
\hline & 2 & 97 & 6,25 & 2,06 \\
\hline & 3 & 116 & 6,24 & 0,86 \\
\hline & 4 & 113 & 6,20 & 1,77 \\
\hline & 5 & 102 & 6,20 & 0,98 \\
\hline & 6 & 119 & 6,15 & 2,52 \\
\hline & 7 & 109 & 6,09 & 2,75 \\
\hline & 8 & 108 & 6,05 & 6,48 \\
\hline & 9 & 39 & 6,05 & 2,06 \\
\hline
\end{tabular}


phic) $(54,24 \%)$ and 1 IV +4 II $(41,95 \%)$, besides the univalent X (Fig. 2a, b) (Table 2). In cells at diakinesis with six bivalents ( 56 cells) two medium sized bivalents are heteromorphic (Fig. 2a); homomorphic bivalents present one or two chiasmata and they are never seen as univalents. In cells at diakinesis with the quadrivalent ( 44 cells), this is always present as a chain, the ring configura-

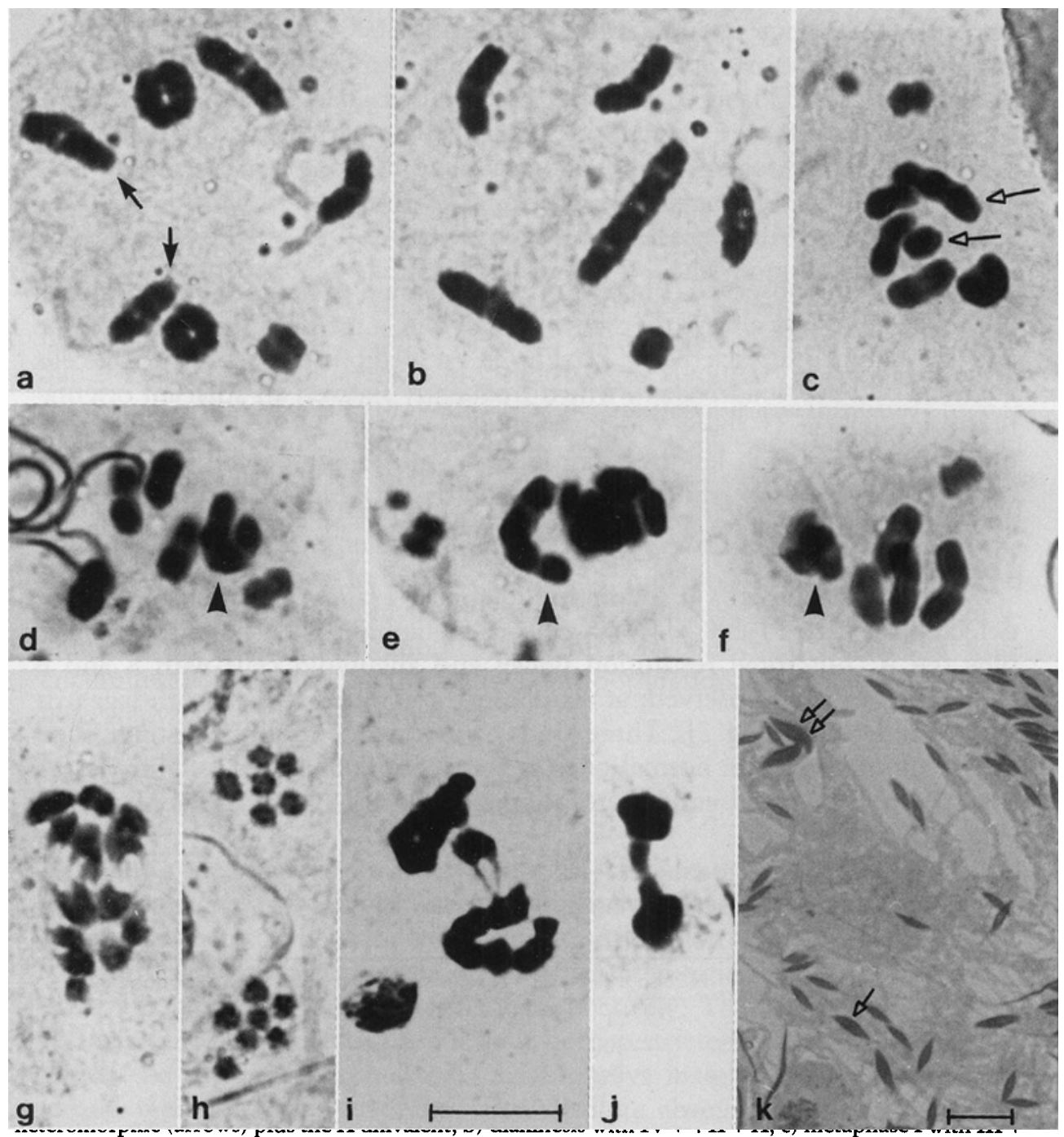

I (empty arrows); $\mathrm{d}-\mathrm{f}$ ) metaphase I: the IV orientates adjacently adopting an U shape (d) or a $\mathrm{C}$ shape (e), or shows an alternate orientation (f); g) anaphase I; h) telophase II; i) anaphase I with laggards; i) anaphase II with lagging chromosomes; $k$ ) normal spermatids, and macrospermatids type I (arrow) and type II (double arrow). Arrowheads point the quadrivalent. $B a r=10 \mu \mathrm{m}$ in $(\mathrm{a}-\mathrm{j})$ and $20 \mu \mathrm{m}$ in $(\mathrm{k})$. 
TABLE 2 - Meiotic configurations in the individual heterozygous for the reciprocal translocation

\begin{tabular}{cccc}
\hline Meiotic configurations & $\begin{array}{c}\text { Number } \\
\text { of chiasmata }\end{array}$ & $\begin{array}{c}\text { Number of cells at } \\
\text { Diakinesis-Metaphase I }\end{array}$ & \% of cells \\
\hline 6 II+X & 6 & 77 & 54,24 \\
(two of them heteromorphic) & 7 & 47 & \\
1 IV+4 II+X & 8 & 4 & 41,95 \\
& 7 & 59 & \\
1 IV+3 II+2 I+X & 8 & 2 & 0,42 \\
1 III+1 I+4 II+X & 9 & 1 & 3,39 \\
Total & 6 & 2 & \\
\hline
\end{tabular}

tion never being observed (Fig. 2b). The disposition of the four chromosomes in the lineal IV was always the same: a small one, a medium sized, a large one and another medium sized (Fig. 2b, Fig. 3). At metaphase I, 56 of the 132 cells analyzed had the quadrivalent, which frequently showed an adjacent orientation adopting an $U$ shape $(56,36 \%)$ or a $C$ shape $(34,55 \%)$; the alternate orientation was much less frequent $(7,27 \%)$ and only one cell with a lineal disposition was observed (1,82\%) (Fig. 2d-f, Fig. 3). Mean chiasma frequency at diakinesis-metaphase I was 6,86 , higher than in the other specimens (Table 1).

In $32 \%$ of the cells at anaphase I-telophase I lagging chromosomes were detected (Fig. 2i) (Table 3). Most cells at metaphase II had 6 chromosomes plus the $\mathrm{X}$, but some restitution nuclei and aneuploid cells with 8 and 6 chromosomes were observed; at anaphase II-telophase II cells with laggards were also detected (Fig. 2j). Three kinds of spermatids could be distinguished according to their size: normal ones, macrospermatids type I (slightly larger than the normal ones) and macrospermatids type II (twice the normal size) (Fig. 2k).

TABLE 3 - Number of normal and abnormal cells in the individual heterozygous for the reciprocal translocation.

\begin{tabular}{lccc}
\hline \multicolumn{1}{c}{ Meiotic stage } & $\mathrm{N}^{\circ}$ of normal cells & $\mathrm{N}^{\circ}$ of abnormal cells & \% of abnormal cells \\
\hline Anaphase I - Telophase I & 21 & 10 & 32 \\
Metaphase II & 40 & (a) 6 & 12 \\
& & (b) 3 & 6 \\
Anaphase II - Telophase II & 5 & (c) 1 & 2 \\
Spermatids & 984 & (d) 50 & 37,5 \\
& & (e) 17 & 4,8 \\
(a) Restitution nuclei; (b) metaphase II with 8 chromosomes (one in excess); (c) metaphase II with 6 \\
chromosomes; (d) macrospermatids type I; (e) macrospermatids type II.
\end{tabular}




\section{DISCUSSION}

Largus rufipennis constitutes a very interesting species from a cytogenetic point of view. It possess a low diploid number, chromosomes of relatively large size and a great variability in chiasma frequency and distribution (PIZA 1946; Mola and PAPESCHI 1993). Previous reports on the species describe the presence of $B$ chromosomes, univalents and ring bivalents in a variable frequency; the latter is a remarkable characteristic since most Heteroptera present as a rule only one chiasma per bivalent (UESHIMa 1979; Manna 1984).

In the present report, karyotype and meiotic behaviour from all individuals of Largus rufipennis from Tornquist and Costanera Norte (Buenos Aires Province) and from all but one specimen from Itaembé (Misiones Province), agree with those previously described in Santo Tomé population (Corrientes Province) (Mola and PAPESCHI 1993). Mean chiasma frequency in the specimens here analyzed is within the range observed in most individuals from Santo Tomé. While differences in mean chiasma frequency are not significant between Tornquist and Costanera Norte populations, it is significantly higher in the Itaembé population. In the Santo Tomé population, individuals fall in three different categories according to the frequency of cells with desynaptic univalents: low $(<3 \%)$, medium $(3-10 \%)$ and high $(>10 \%)$. All the specimens from Itaembé and most individuals from Buenos Aires Province belong to the first of these categories. In Costanera Norte population one specimen showed a medium frequency of univalents, while in Tornquist population one individual with medium and another with high frequency of univalents were encountered. In contrast to the Santo Tomé population, none of the specimens here analyzed had B chromosomes.

\section{Origin and bebaviour of the quadrivalent}

The appearance of a quadrivalent plus 4 bivalents and the $\mathrm{X}$ univalent in $43 \%$ of the meiotic cells in one individual from Itaembe indicates that the specimen is heterozygous for a reciprocal translocation (Fig. 3a). Theoretically, a quadrivalent can depict a ring or a chain configuration depending upon the presence of four or three chiasmata, respectively. The configuration of the quadrivalent here detected has always been restricted to the chain form, in which the involved chromosomes have always maintained the same order (small, medium, large, medium). The absolute absence of chiasmata in the same pairing region suggests that this region would be very small, making it difficult or even impossible the occurrence of crossing over in it (Fig. 3b).

According to our observations the individual would carry a simple unequal reciprocal translocation between two non homologous chromosomes of medium size, with one of the break points located near a telomeric region. 
Thus, the result of the translocation event is a large and a small chromosomes, respectively (Fig. 3a).

If only two crossovers take place in the quadrivalent, and assuming that their distribution among the three putative recombination regions is random, the expected meiotic configurations are a trivalent plus a univalent, or else two heteromorphic bivalents, the frequency of the former being twice that of the latter. Since in the present report $54 \%$ of the cells present two heteromorphic bivalents while only $3 \%$ show a trivalent plus a univalent, it can be concluded that there are preferential sites for the crossing over to occur. This fact, together with the terminal or subterminal location of chiasmata observed in all other individuals of the populations led us to suggest that crossovers would preferentially occur in only one telomeric region, both in the quadrivalent and also in the two original non translocated chromosome pairs (a and c regions, Fig. 3a, b). Hence, the meiotic recombination in the quadrivalent would occur first in these areas, giving rise to two heteromorphic bivalents; since mean chiasma frequency in this individual is almost $7(6,86)$ the remaining crossing over could take place at the quadrivalent (d region; Fig. 3a, b) or in any other autosomal pair (which would be present as a ring bivalent).

In Heteroptera, kinetic activity during meiosis is restricted to one pair of telomeric regions (telokinetic activity); at metaphase I, bivalents orientate axially in the equatorial plane and telomeric regions lead the anaphasic movement to the poles. In the quadrivalent only two telomeric regions are free to attach to the spindle fibers, and they could be orientated to the same pole (adjacent orientation, type $\mathrm{U}$ shape) $(56,36 \%)$ or to different poles (adjacent orientation, type $\mathrm{C}$ shape + alternate orientation + lineal orientation) $(34,55 \%$ $+7,27 \%+1,82 \%$ ) (Fig. 3c). However, the quadrivalent should have other sites for spindle fibers attachment besides the telomeric ones, specially in the $\mathrm{C}$ shaped quadrivalent and the alternate orientated. The existence of alternative sites with meiotic kinetic activity had been already suggested in Heteroptera to account for the migration of ring bivalents (CAMACHO et al. 1985; PAPESCHI and Mola 1995).

Both the lineal orientation and the adjacent one (which represent approximately $93 \%$ of the cells) result in unbalanced gametes due to genetic duplications and deficiencies. On the other hand, only the alternate orientation gives rise to balanced gametes. Assuming that bivalents have a random orientation, in the cells with six bivalents half of the gametes will then be balanced and the remaining, unbalanced ones. Consequently, the final percentage of balanced gametes in the heterozygote is expected to be very low.

Fig. 3. - Origin and orientation of the quadrivalent. 
a: Unequal reciprocal translocation

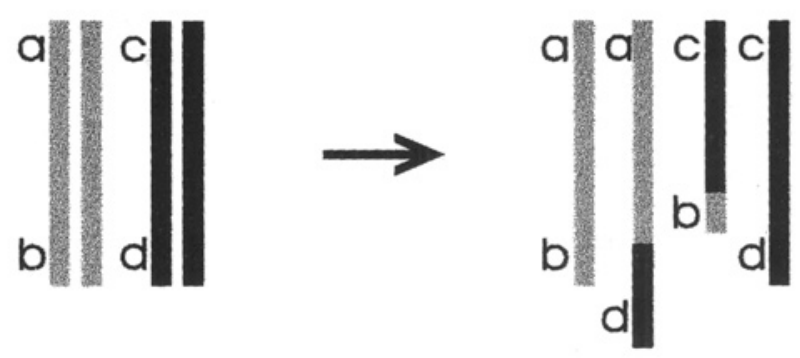

b: Pachytene configuration

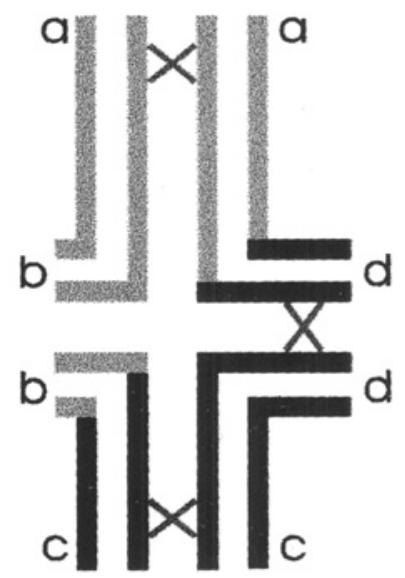

c: Metaphase I orientation

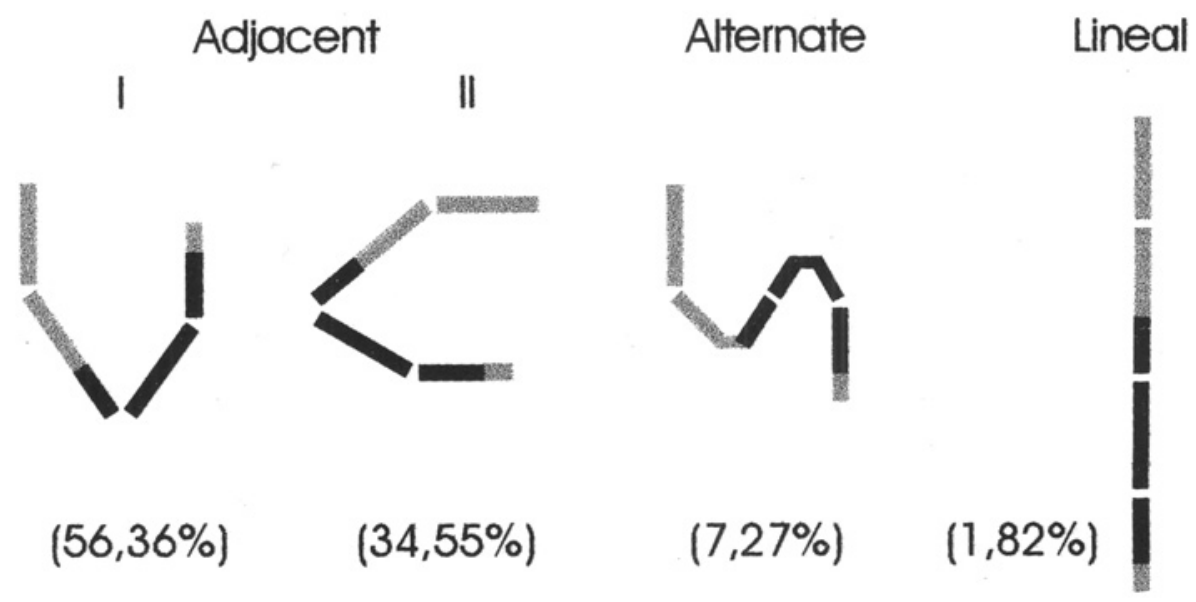




\section{Reciprocal translocations in karyotype evolution of bolokinetic systems}

Reciprocal translocations are rare events in organisms with holokinetic chromosomes. The unique report of heterozygosity for a reciprocal translocation in plants with holokinetic chromosomes has been in an irradiated seedling of Luzula purpurea (Juncaceae) (CASTRo et al. 1954; NoRDENSKIöLD 1963). The meiotic behaviour of the quadrivalent during the first meiotic division was regular, a fact that could be accounted for the type of meiosis (postreductional) which is characteristic of the Juncaceae. However, fertility of the individual was reduced due to the missegregation of chromosomes during the second meiotic division.

Within the Homoptera the presence of reciprocal translocations has been reported in the aphid Myzus persicae (Aphididae), both in natural and glasshouse populations (BLACKMAN and TAKAdA 1975, 1977; Blackman et al. 1995). Some clones of the species bore a simple reciprocal translocation in heterozygous condition. BLACKMAN et al. (1995) reported that the heterozygosity for the reciprocal translocation is associated with insecticide resistance, a characteristic that would confer the species a higher fitness. The maintenance of the heterozygosity could be favored by the particular life cycle of the species (it reproduces regularly by apomictic parthenogenesis except when temperature conditions led to the appearance of a bisexual phase), and the achiasmatic nature of the male meiosis.

In Buthidae (Scorpionida) the occurrence of this kind of rearrangement is much more widespread; natural populations of Lychas, Isometroides, Isometrus, Tityus and Rhopalurus show polymorphisms and polytypisms for simple and multiple reciprocal translocations in heterozygous condition (PIzA 1948, 1951, 1957; TAKAHASHI 1976; SHANAHAN 1989a). In scorpions, both with holokinetic and monocentric chromosomes, male meiosis is achiasmatic and of pre-reductional type. The hypothetical orientation of multivalents "above and below" proposed by SHANAHAN (1989a) and the absence of chiasmata during meiosis would be the cytogenetical features allowing the establishment of this kind of rearrangement.

Finally, our present observations in L. rufipennis (Heteroptera) reveal that there are not major meiotic irregularities, but the frequency of balanced gametes in the reciprocal translocation heterozygote is very low due to duplications and deficiencies. This would be a direct consequence of the type of meiosis characteristic in the order, chiasmatic and pre-reductional with telokinetic activity. Accordingly, the probability for this type of chromosome rearrangement to be established as a balanced polymorphism or even to become fixed in the population is also very low.

It has been suggested that reciprocal translocations have greater chances of establishing in species with holokinetic chromosomes, since all the products of reciprocal translocations are transmissible at meiosis (WHITE 1973). How- 
ever, taking in consideration the frequency of reciprocal translocations in the different groups of organisms with holokinetic chromosomes, and the cytologi$\mathrm{cal}$ and genetic consequences of this rearrangement type, it can be assumed that in general they are strongly negatively selected, having played an important role only in the karyotype evolution of Buthidae so far (SHANAHAN 1989a). Furthermore, since in Scorpionidae (family of scorpions with monocentric chromosomes) polymorphisms and polytypisms for reciprocal translocations (centric fusions) are also highly frequent (SHANAHAN 1989b), it can be concluded that this chromosome rearrangement should be characteristic of the order Scorpionida, not directly related to the holokinetic nature of the chromosomes in Buthidae but with the achiasmatic male meiosis.

Acknowledgements. - This work has been supported by grants from the Comisión de Investigaciones Cientificas de la Provincia de Buenos Aires (CIC), National Council of Scientific and Technological Research (CONICET) (PIP 4217 to Dr. L. Poggio), National University of La Plata, and Buenos Aires University (EX 170 to Dr. L. Poggio and Dr. L. Mola) and from 127/y Agencia Nacional de Promocion Cientifica y Tecnologica PICT 97 01-00000-00754. The authors thank Dr. Axel Bachmann for the taxonomical determination of the specimens studied in the present report, Dr. Lidia Poggio and Dr. Arturo Wulff for critical reading of the manuscript, and Lic. B. Gonzalez for her advice in the statistical analysis.

\section{REFERENCES}

BLACKMAN R.L. and TAKAda H., 1975. - A naturally occurring cbromosomal translocation in Myzus persicae (Sulzer). J. Ent. (A), 50: 147-156.

-, 1977. - The inberitance of natural chromosomal polymorphisms in the aphid Myzus persicae (Sulzer). Genetica, 47: 9-15.

Blackman R.L., Spence J.M., Fiejo L.M. and Devonshire A.L., 1995. - Chromosomal location of the amplified esterase genes conferring resistance to insecticides in Myzus persicae (Homoptera: Aphididae). Heredity, 75: 297-302.

Camacho J.P.M., Belda J. and Cabrero J., 1985. - Meiotic behaviour of the holocentric chromosomes of Nezara viridula (Insecta, Heteroptera) analysed by C-banding and silver impregnation. Can. J. Cytol., 27: 490-497.

Castro D., Noronha-Wagner M. and Camara A., 1954. - Two X-ray induced translocations in Luzula purpurea. Genetica Iberica, 6: 3-18.

ManNA G.K., 1984. - Chromosomes in evolution in Heteroptera. In: Sharma A.K. and Sharma A., (Eds), "Chromosomes in Evolution of Eukaryotic groups", 2: 189-225. CRC Press, Florida.

Mola L.M. and PAPeschi A.G., 1993. - Meiotic studies in Largus rufipennis (Castelnau) (Largidae, Hetroptera): frequency and behaviour of ring bivalents, univalents and B chromosomes. Heredity, $71: 33-40$.

NoRDENSKIÖLD H., 1963. - A study of meiosis in the progeny of X-irradiated Luzula purpurea. Hereditas, 49: 33-47.

PAPESCHI A.G., 1994. - Chromosome rearrangements in Belostoma plebejum (Stal) (Belostomatidae, Heteroptera). Caryologia, 47: 223-230.

-, 1996. - Sex chromosome polymorphism in a species of Belostoma (Belostomatidae, Heteroptera). Hereditas, 124: 269-274.

Papeschi A.G. and Mola L.M., 1990. - Meiotic studies in Acanonicus babni (Stal) (Coreidae, Heteroptera). II. Male chromosome bebaviour in a spontaneous inversion mutant. Genetica, 81: 59-66. 
-, 1995. - Secondary constriction flanking regions bear alternative sites of spindle fiber attachment in Pachylis argentinus and Nezara viridula (Heteroptera). Chrom. Res., 3 (Suppl. 1): 120.

PIZA S. DE T., 1946. - Comportamento dos cromossomios na meiose de Euryophthalmus rufipennis Laporte (Hemiptera, Pyrrbocoridae). An. Esc. Sup. Agr. "Luiz de Queiroz", 10: 156-186.

-, 1948. - Primeiras observações sôbre os cromossōmios de Tityus trivittatus Krpln (Scorpiones, Butbidae). Rev. Agric. São Paulo, 23: 177-180.

-, 1951. - Primeiras observaçōes sôbre os cromossōmios de Tityus mutuendus Pocock (Scorpiones, Butbidae). Sci. Genetica, 4: 162-167.

-, 1957. - The chromosomes of Rhopalurus (Scorpiones, Butbidae). An. Esc. Sup. Agr. "Luiz de Queiroz", 89: 565-568.

Shanahan C.M., 1989a. - Cytogenetics of Australian scorpions. I. Interchange polymorphism in the family Buthidae. Genome, 32: 882-889.

-, 1989b. - Cytogenetics of Australian scorpions. II. Chromosome polymorphism in species of Urodacus (family Scorpionidae). Genome, 32: 890-900.

Sokal R.R. and Rohlf F.J., 1981. - Biometry. W.H. Freeman and Co., New York, USA.

TAKAHASHI C.S., 1976. - Cytogenetical studies on the effects of high natural radiation levels in Tityus babiensis (Scorpiones, Butbidae) from Morro do Ferro, Brazil. Radiat. Res., 67: 371-381.

Thomas D.B. JR., 1987. - Chromosome evolution in the Heteroptera Hemiptera. Agmatoploidy versus Aneuploidy. Ann. Entomol. Soc. Am., 80: 720-730.

Ueshima N., 1979. - Hemiptera II. Heteroptera. In: B. John (ed), “Animal Cytogenetics”, 3; Insecta 6. Borntraeger, Berlin.

WhIte M.J.D., 1973. - Animal Cytology and Evolution. Cambridge University Press, London.

Received 1 September 1998; accepted 18 December 1998 